\title{
EFFICACY AND SAFETY OF TRABECULECTOMY WITH MITOMYCIN C FOR CHILDHOOD GLAUCOMA: A STUDY OF RESULTS WITH LONG-TERM FOLLOW- UP
}

\author{
Jair Giampani Junior, Adriana Silva Borges-Giampani, José Carlos Eudes \\ Carani, Ernst Werner Oltrogge, Remo Susanna Junior
}

doi: $10.1590 / \mathrm{S} 1807-59322008000400002$

\begin{abstract}
Giampani Jr J, Borges-Giampani AS, Carani JCE, Oltrogge EW, Susanna Jr. R Efficacy and safety of trabeculectomy with mitomycin c for childhood glaucoma: a study of results with long-term follow-up. Clinics. 2008;63:421-6.
\end{abstract}

OBJECTIVE: To evaluate the safety and effectiveness of trabeculectomy with mitomycin $\mathrm{C}$ in the management of childhood glaucoma.

INTRODUCTION: The use of antifibrotic agents enhances the success of trabeculectomy performed in both adults and children.

METHODS: A retrospective chart review (1991-2001) of 114 patients (114 eyes) from 0-14 years of age with congenital or developmental glaucoma. These patients underwent trabeculectomy with mitomycin but had not been previously treated with any antifibrotic agent.

RESULTS: The mean patient age was $57.36+/-51.14$ months (range: $0.5-168$ months). Treatment was considered successful in 63 eyes $(55.26 \%)$, with a mean intraocular pressure of $12.11+/-3.98 \mathrm{mmHg}$. For patients categorized as successfully treated, the mean follow-up time was $61.16+/-26.13$ months (range 12-113 months). A post-surgical intraocular pressure of $<16$ was observed in 47 eyes. The life-table success rates for intraocular pressure control at 24, 36, 48, and 60 months were $90.2 \%, 78.7 \%, 60.7 \%$ and $50.8 \%$, respectively. The cumulative probability of failure was $40.8 \%$ at 12 months. Following surgery, endophthalmitis appeared in eight eyes (4.88\%) after an average 36.96 months (range: 1.7-106 months). Other complications included expulsive hemorrhage, flat anterior chamber and bleb leak.

DISCUSSION: It has been reported in pediatric patients that trabeculectomy without adjunctive antimetabolites achieves a successful outcome in 30\% to 50\% of cases. In our study, treatment was considered successful in 63 eyes (55.26\%) within 61.16 +/- 26.13 months of follow-up.

CONCLUSIONS: Trabeculectomy with mitomycin is safe and effective for short-term or long-term treatment of congenital or developmental glaucoma. The frequency of bleb-related endophthalmitis was no higher in these patients than that described in adults.

KEYWORDS: Trabeculectomy. Childhood glaucoma. Mitomycin. Complications. Efficacy.

\section{INTRODUCTION}

Congenital glaucoma is a major cause of blindness in children, despite its low incidence (1:10,000 births). ${ }^{1}$ Its management is primarily surgical, with trabeculotomy

Department of Ophthalmology - Hospital das Clínicas da Faculdade de Medicina da Universidade de São Paulo - São Paulo/SP, Brazil.

Email: jgiampani@ig.com.br

Received for publication on March 07, 2008

Accepted for publication on April 03, 2008 and goniotomy being the procedures of first choice in the majority of cases of primary congenital glaucoma. ${ }^{2-4}$ If intraocular pressure is not adequately controlled by these procedures, trabeculectomy is usually the next course of action. The success rate of trabeculectomy in primary congenital glaucoma varies. Most series achieve a success rate of $35-85 \%$, depending on the number of previous surgeries, the length of follow-up and the population studied. $^{5-9}$

The success of trabeculectomy performed in adults 
or children is enhanced by the use of antifibrotic agents, which suppress fibroblast activity. ${ }^{10-16} \mathrm{~A}$ study with a shorter follow-up reported a success rate of $67 \%$ using intraoperative mitomycin $\mathrm{C}$ as an adjunctive therapy to trabeculectomy performed for the treatment of congenital or developmental glaucoma. ${ }^{17}$

To the best of our knowledge, this study reports a larger series and a longer follow-up than any previous study of trabeculectomy and adjunctive mitomycin treatment of childhood glaucoma.

The purpose of this manuscript is to evaluate the safety and effectiveness of trabeculectomy with mitomycin $\mathrm{C}$ in the management of childhood glaucoma.

\section{MATERIALS AND METHODS}

We reviewed charts (1991-2001) of 125 patients who ranged from 0-14 years old at the time of diagnosis and surgery. All had presented with primary congenital glaucoma or glaucoma associated with other developmental anomalies, and all were treated with trabeculectomy and adjunctive intraoperative mitomycin C. Cases in which any antifibrotic agent, including mitomycin, had been used in any prior surgery were excluded.

All eyes in which mitomycin $\mathrm{C}$ was used had poor surgical prognoses, including those of patients at a very young age, patients with aphakia and patients with multiple previous glaucoma procedures. This study included some cases in which trabeculotomy, goniotomy or trabeculectomy without antimetabolites had failed previously. Patients who had not undergone surgery but had a corneal diameter of $>14 \mathrm{~mm}$, as well as patients with other developmental glaucomas such as Peter's anomaly, Sturge-Weber syndrome, congenital aniridia or Axenfeld-Rieger (AR) disease, were also included.

All surgeries were performed by one of two authors, both using the same technique. Briefly, after a limbal-based conjunctival flap was prepared, a 2 X $3 \mathrm{~mm}$ rectangular scleral flap of one-third to one-half of the scleral thickness was cut toward the clear cornea. The incision was made in the superior portion of the globe. A solution of $0.2 \mathrm{mg} / \mathrm{mL}$ mitomycin $\mathrm{C}$ was prepared, and a $4 \times 4 \mathrm{~mm}$ surgical sponge soaked in the solution was held in contact under the scleral flap, with conjunctival/Tenon laid over it, for five minutes. After that, the entire area was irrigated with $40 \mathrm{~mL}$ of saline solution. The procedure was then completed as a standard trabeculectomy. However, some minor modifications were made: sclerectomy was performed using a number-11 blade. Iridectomy was not performed in any case because these eyes had a very deep anterior chamber and there was a low risk of internal blockage. The scleral flap was sutured more securely than usual, using a 10-nylon suture. The conjunctival/Tenon layer was sutured with slightly more tissue enclosed in each stitch. Topical cycloplegics, steroids and antibiotics were administered postoperatively. Other than digital massage, no manipulations (such as bleb revision or suturelysis) were performed unless deemed absolutely necessary. Hypotensive drugs were utilized only when the target-pressure was not achieved.

Intraocular pressure was measured before and after surgery using a Goldman tonometer. When necessary, children were sedated with chloral hydrate syrup (25-50 mg/ $\mathrm{kg}$ body weight) for the measurement of intraocular pressure. As some of the patients had some degree of corneal opacity that prevented the adequate evaluation of the optic disc, only intraocular pressure was analyzed.

The clinical evaluation of the results included the determination of intraocular pressure and the identification of any unexpected complications.

Eyes with an intraocular pressure between 5 and $21 \mathrm{mmHg}$ after surgery with or without the use of medication were considered successfully treated. If the intraocular pressure remained under $21 \mathrm{mmHg}$ without the use of any medication, the treatment was considered an absolute success. Eyes with an intraocular pressure greater than $21 \mathrm{mmHg}$ at the last visit or eyes with complications (phthisis, retinal detachment or endophthalmitis) were considered a failure.

The end-point of the study was either the final visit (after at least one year of follow-up), when the patient needed a subsequent operation to control intraocular pressure or when the patient developed any other complications, such as phthisis bulbi, retinal detachment or endophthalmitis.

To evaluate the efficacy of the procedure, when a patient had surgery on both eyes, one eye was randomly selected to be evaluated for this study. To assess safety, we considered all surgeries performed without randomization.

Surgical outcome was evaluated using cumulative probability life-table analysis (Kaplan-Meier). A P-value $<0.05$ was considered significant. Given the study's retrospective and case series nature, approval by the Institution Ethics Committee was waived.

\section{RESULTS}

A total of 125 patients who underwent trabeculectomy with primary mitomycin C after 1991 were evaluated. Eleven patients were excluded because they did not fulfill the inclusion criteria. The remaining 114 cases (164 eyes) were included.

The group of subjects consisted of $65(57 \%)$ males and $49(43 \%)$ females. The total mean age was $57.36+/-51.14$ months, ranging from 0.5 to 168 months. The most common diagnosis was primary congenital glaucoma, accounting 
for 88 of the cases. Eleven patients had AR disease, and five had Sturge-Weber disease. Others types of glaucoma included four cases of aniridia, two of Peter's disease and three patients with aphakic glaucoma after cataract surgery. Three patients remained undiagnosed.

The mean preoperative intraocular pressure was 27.42 $+/-5.91 \mathrm{mmHg}$ in the successfully treated group and 30.89 $+/-7.21 \mathrm{mmHg}$ in the failed-treatment group $(\mathrm{p}=0.0085$, Student's t-test) (Table 1). Sixty-three eyes were considered successfully treated (with a mean intraocular pressure of $12.11+/-3.98 \mathrm{mmHg}$ using an average of 0.47 topical glaucoma control medication) on the final visit -- an overall success rate of $55.26 \%$. Forty-seven eyes $(41.23 \%)$ showed an intraocular pressure of $<16 \mathrm{~mm}$ HG after surgery. The mean age of the subjects successfully operated on was 58.75 +/- 49.92 months.

The mean length of follow-up for the successfully treated eyes was $61.16+/-26.13$ months (ranging from 12 to 113 months). Forty-two eyes (37.84\%) required no topical glaucoma control medication (absolute success), fourteen eyes $(12.61 \%)$ required one drug and seven eyes $(6.31 \%)$ required two or more drugs. A total of 21 successfully treated eyes required medication after surgery (33.34\%). There were no topical medication data available for three patients (all from the failed-treatment group). Within the successfully treated group (63 eyes), 42 eyes had previously been operated upon.

The cumulative probabilities of success (Kaplan-Meier plot) for one eye of each patient were $90.2 \%$ at 24 months,
$78.7 \%$ at 36 months, $60.7 \%$ at 48 months and $50.8 \%$ at 60 months (Figure 1).

Bleb revision (including needling) and/or suturelysis were not performed in any case from the successfully treated group.

Surgical success and failure rates according to the preoperative intraocular pressure, age, number of previous surgeries and diagnosis can be seen in Tables 1, 2, 3, and 4 , respectively. There was only a statistically significant difference $(\mathrm{p}<0.05)$ in the preoperative intraocular pressure analysis ( $p=0.0085$, Student's t-test). The $\mathrm{p}$-values for the others risk factors (age and previous surgery) were 0.67 and 0.32 , respectively.

Surgical failure occurred in 51 eyes $(44.73 \%)$. The mean age of these patients was $55.69+/-53.03$ months. External blockage was the cause of failure in all cases. In the failed-treatment group, 40 eyes (35.09\%) had previously been operated upon. Of the 164 eyes operated upon, endophthalmitis developed in eight $(4.88 \%)$. The average time between surgery and diagnosis of endophthalmitis was 36.96 months (ranging from 1.7 to 106 months) (Table 5).

One expulsive hemorrhage occurred during surgery, causing a loss of light perception in that eye. A flat anterior chamber was observed in five eyes (3.04\%), hyphema in two eyes $(1.21 \%)$ and bleb leak in one eye $(0.6 \%)$ (Table 6$)$.

\section{DISCUSSION}

Childhood glaucoma is a disease that typically requires

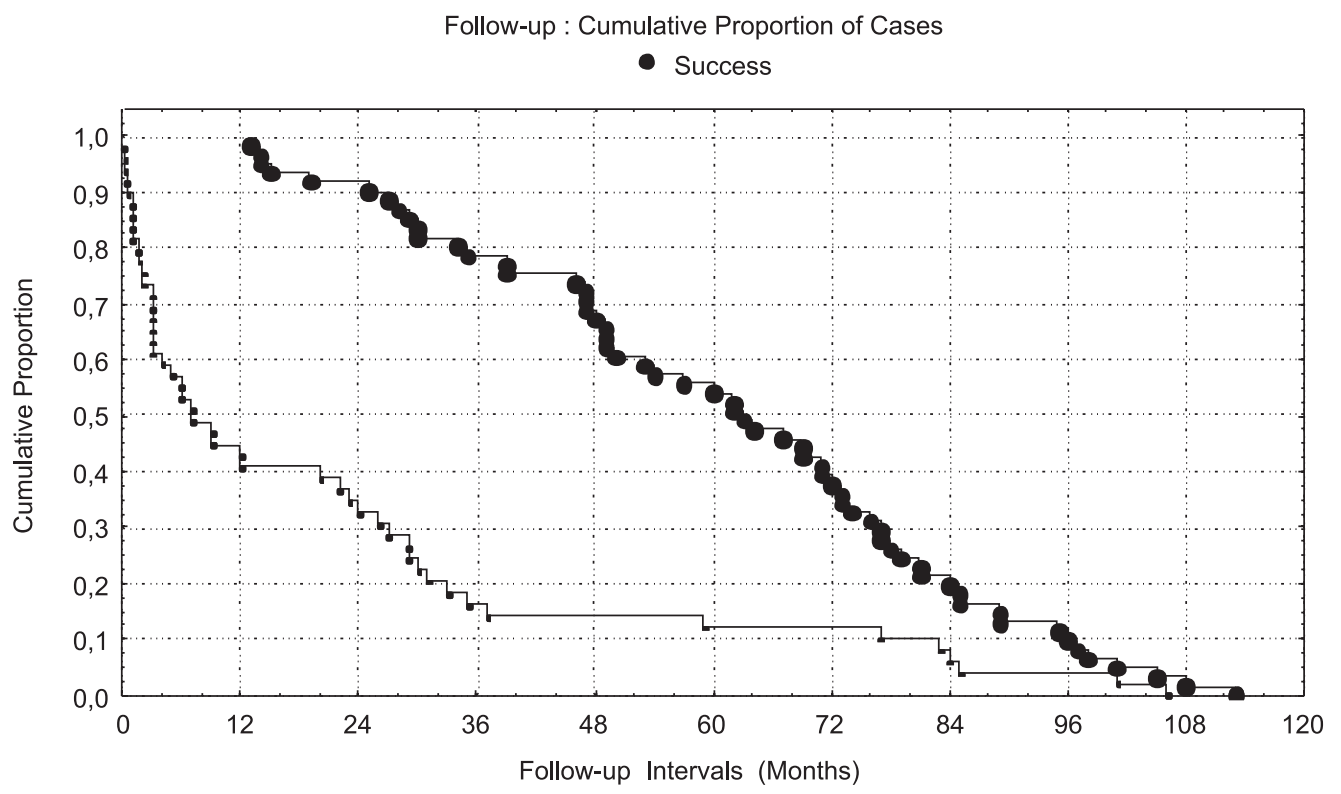

Figure 1 - Cumulative proportion of success ${ }^{\Psi}$

${ }^{\Psi}$ Number of patients at risk for failure at each time interval: 56 (at 24 months), 48 (at 36 months), 41 (at 48 months), 33 (at 60 months), 23 (at 72 months), 12 (at 84 months), 6 (at 96 months), 1 (at 108 months) and 0 (at 120 months). 
Table 1 - Iintraocular pressure (IOP) follow-up

\begin{tabular}{|c|c|c|c|c|c|}
\hline & $\begin{array}{l}\text { Preoperative } \\
\text { IOP MEAN SD }\end{array}$ & $\begin{array}{c}1 \text { month } \\
\text { IOP MEAN SD }\end{array}$ & $\begin{array}{c}1 \text { year } \\
\text { IOP MEAN SD }\end{array}$ & $\begin{array}{c}2 \text { years } \\
\text { IOP MEAN SD }\end{array}$ & $\begin{array}{c}\text { Final visit I } \\
\text { OP MEAN SD }\end{array}$ \\
\hline Success & $27.42 \pm 5.91$ & $11.05 \pm 5.77$ & $11.72 \pm 4.24$ & $11.61 \pm 4.62$ & $12.11 \pm 3.98$ \\
\hline Failure & $30.89 \pm 7.21$ & $13.46 \pm 7.19$ & $12.62 \pm 7.22$ & $15.5 \pm 8.63$ & $24.6 \pm 10.21$ \\
\hline Total & 28.97 & 12.03 & 11.97 & 12.52 & 17.31 \\
\hline p-value & $0.0085^{*}$ & 0.0649 & 0.5067 & $0.03 *$ & $0.0000001 *$ \\
\hline
\end{tabular}

* significant $(\mathrm{p}<0.05)$ Student's $\mathrm{t}$ test

Table 2 - Success and failure correlated with age

\begin{tabular}{lccccc}
\hline Status & $\begin{array}{c}0-12 \\
\text { months }\end{array}$ & $\begin{array}{c}13-60 \\
\text { months }\end{array}$ & $\begin{array}{c}61-120 \\
\text { months }\end{array}$ & $\begin{array}{c}121-168 \\
\text { months }\end{array}$ & Total \\
\hline Success n & 15 & 21 & 15 & 09 & 60 \\
$\%$ & $50 \%$ & $52.5 \%$ & $65.22 \%$ & $52.94 \%$ & 60 \\
\hline Failure n & 15 & 19 & 08 & 08 & 50 \\
$\%$ & $50 \%$ & $47.5 \%$ & $34.78 \%$ & $47.06 \%$ & 50 \\
\hline Total n & 30 & 40 & 23 & 17 & 110 \\
$\%$ & $100 \%$ & $100 \%$ & $100 \%$ & $100 \%$ & \\
\hline $\begin{array}{l}\text { No data } \\
\text { available }\end{array}$ & & & & 04 \\
\hline
\end{tabular}

$\mathrm{p}=0.67014$ chi-square

Table 3 - Success and failure correlated with previous surgery

\begin{tabular}{lccc}
\hline Status & \multicolumn{2}{c}{ Previous Surgery } & \multirow{2}{*}{ Total } \\
\cline { 2 - 3 } & YES & NO & \\
\hline Success $n$ & 42 & 18 & 60 \\
$\%$ & $38.18 \%$ & $16.36 \%$ & $54.55 \%$ \\
\hline Failure $n$ & 40 & 10 & 50 \\
$\%$ & $36.36 \%$ & $9.09 \%$ & $45.45 \%$ \\
\hline Total n & 82 & 28 & 110 \\
$\%$ & $74.55 \%$ & $25.45 \%$ & $100 \%$ \\
\hline No data available & & & 04
\end{tabular}

$\mathrm{p}=0.32755$ chi-square

Table 4 - Success and failure correlated with diagnosis

\begin{tabular}{lccccccc}
\hline Status & CG & AR & SW & AD & PE & CC & Total \\
\hline Success n & 46 & 09 & 03 & 02 & 01 & 00 & 61 \\
$\%$ & 53.48 & 81.2 & 60.0 & 50.0 & 50.0 & 0.0 & 55.0 \\
\hline Failure n & 40 & 02 & 02 & 02 & 01 & 03 & 50 \\
$\%$ & 46.52 & 18.8 & 40.0 & 50.0 & 50.0 & 100.0 & 45.0 \\
\hline Total n & 86 & 11 & 05 & 04 & 02 & 03 & 111 \\
$\%$ & 100.0 & 100.0 & 100.0 & 100.0 & 100.0 & 100.0 & 100.0 \\
\hline $\begin{array}{l}\text { No data } \\
\text { available }\end{array}$ & & & & & & & 03 \\
\hline
\end{tabular}

CG - Congenital Glaucoma; AR - Axenfeld - Rieger; SW - Sturge - Weber; AD - Aniridia; PE - Peters; CC - Congenital Cataract
Table 5 - Endophthalmitis following surgery

\begin{tabular}{lc}
\hline Time after surgery (months) & Number of eyes \\
\hline $0-12$ & $03(37.5 \%)$ \\
$13-24$ & $00(0 \%)$ \\
$>24$ & $05(62.5 \%)$ \\
\hline Total & $08(100 \%)$ \\
\hline
\end{tabular}

Table 6 - Complications

\begin{tabular}{lc}
\hline Complication & Total N=164 \\
\hline Endophthalmitis & $8(4.88 \%)$ \\
Hyphema & $2(1.21 \%)$ \\
Leakage & $1(0.6 \%)$ \\
Flat anterior chamber & $5(3.04 \%)$ \\
Expulsive & $1(0.6 \%)$ \\
\hline Total & $17(10.36 \%)$ \\
\hline
\end{tabular}

surgery as early as possible. Goniotomy and trabeculotomy are usually the procedures of first choice for primary congenital glaucoma. Both are safe and have a low incidence of complications. ${ }^{3,18}$ When goniotomy and trabeculotomy fail, trabeculectomy is the usual course of action. However, the success rate of initial trabeculotomy as a treatment for childhood glaucoma can be reduced by the presence of other ocular anomalies (Peters, Sturge-Weber, Aniridia, etc.) or by a corneal diameter of $>14 \mathrm{~mm} \cdot{ }^{16}$

In pediatric patients (patients less than 18 years of age), it has been reported that trabeculectomy without adjunctive antimetabolites achieves a successful outcome in $30 \%$ to $50 \%$ of cases..$^{5-7}$ The highest success rate $(50 \%)$ was reported in a study with a relatively short follow-up (mean 15.5 months $)^{5}$. Studies with longer follow-ups report success rates of $30 \%$ to $35 \%$.

In comparison to 5-fluorouracil, MMC is a more potent inhibitor of fibroblast proliferation and can be used intraoperatively, making it an attractive alternative for children for whom previous surgery has failed. Clinical studies comparing these two antifibrotic agents have 
demonstrated that MMC has a greater success rate and induces a greater reduction in the degree of intraocular pressure. $^{19-22}$

Susanna et $\mathrm{al}^{17}$ achieved an overall success rate of $67 \%$ with a mean follow-up of 17 months in a series of 56 patients (79 eyes) with primary congenital glaucoma or developmental glaucomas treated with trabeculectomy and adjunctive MMC. This success rate is higher than the $55.26 \%$ described in the present study. This discrepancy is likely attributable to the longer follow-up (61.16 months) applied in our study. Beck and associates ${ }^{23}$ described a success rate of $58 \%$ after a 24-month follow-up, although they had a large number of aphakic patients and a mean age of 91.2 months (7.6 years old). Among the cases that we studied, there were only two aphakic patients, and, as previously stated, the mean age was 57.36 months (4.78 years old). Sidoti et al. ${ }^{24}$ showed a success rate of $59 \%$ in a case series of 29 eyes, with a mean follow-up time of 25.1 +/- 16 months. In this paper, the 24- and 36-month life-table success rates for intraocular pressure control were both $59 \%$, versus $90.2 \%$ at 24 months, $78.7 \%$ at 36 months, $60.7 \%$ at 48 months and $50.8 \%$ at 60 months in our study.

In a series of 19 mitomycin $\mathrm{C}$ trabeculectomies, Mandal et $\mathrm{al}^{25}$ described an extremely high $(95 \%)$ success rate. However, their study included only one patient under the age of one year, a factor that may have been instrumental in achieving such a superb success rate. In contrast, we had 30 patients who were less than one year old (including two presenting endophthalmitis), and this group showed a $50 \%$ success rate that was similar to the $42.85 \%$ success rate in patients under the age of one described by Susanna and associates. ${ }^{17}$

In our study, the best success rate $(65.22 \%)$ was achieved in the 61- to 120-month age group, though without a statistically significant difference when compared with the other age groups ( $p=0.7$ chi-square). Miller and Rice ${ }^{26}$ also demonstrated a better prognosis for surgeries performed in older children.

Susanna et $\mathrm{l}^{17}$ noted no difference in the success rate between eyes that had previously been submitted to glaucoma surgery and those that had not. The authors suggested that the results from the group that had no prior glaucoma surgery were skewed by the inclusion of eyes with poor prognoses due to conditions such as AR anomaly, Sturge-Weber syndrome and Aniridia. Beck et $\mathrm{al}^{23}$ demonstrated a lower success rate for the group that had prior glaucoma surgery (55\% vs. $70 \%)$, but without a statistically significant difference. In our study, the success rate was also higher in the group with no previous glaucoma surgery (64.28\% compared with $51.21 \%$ ), but this difference was also not statistically significant ( $p=0.32$ chi-square). In our paper, there was a higher average preoperative intraocular pressure in the failed-treatment group $(30.89+/$ $7.21 \mathrm{~mm} \mathrm{Hg}$ ) than in the successfully treated group (27.42 +/- $5.91 \mathrm{~mm} \mathrm{Hg})(\mathrm{p}=0.0085$ - Student's t-test $)$. These data suggest that higher preoperative intraocular pressure are associated with a greater risk for surgical failure.

Notably, in our series, the AR group demonstrated a better success rate $(81.2 \%)(p=0.031$ difference between the percentages of success) than the primary congenital glaucoma group $(53.48 \%)(\mathrm{p}=0.409$ difference between the percentages). These results are even more intriguing if we consider that $54.54 \%$ of the eyes that had previously been operated on for glaucoma were successfully treated within this group. However, these data should be analyzed carefully because our study only contained a small number of patients with AR $(n=11)$. Others studies with larger series may help to elucidate this question.

Endophthalmitis is a major complication associated with trabeculectomy that has been reported in children who have undergone trabeculectomy with $\mathrm{MMC}^{27}$. In our study, eight of a total of 164 operated eyes (4.88\%) developed endophthalmitis. Beck and associates ${ }^{23}$ reported a higher endophthalmitis incidence $(8 \%)$, while Susanna et al. ${ }^{17}$ reported one case in 79 eyes and Wallace and associates ${ }^{28}$ noted one case in 16 eyes. Mandal et al. ${ }^{25}$ reported no cases of endophthalmitis in a series of 19 eyes. Sidoti et al. ${ }^{24}$ described a higher incidence of infectious complications ( $10 \%$ blebitis and $7 \%$ endophthalmitis), probably due to the higher MMC concentration $(0.5 \mathrm{mg} / \mathrm{ml})$ utilized in their study. Wells et al, ${ }^{29}$ who utilized a limbus-based conjunctival flap, demonstrated the highest reported incidence of endophthalmitis $(15 \%)$ in a series of 20 eyes. In adults, the incidence of endophthalmitis following antimetabolite use ranges from $2 \%$ to $9 \%$. $^{30-32}$

Like Sidoti et al. ${ }^{24}$, we observed a relatively long interval between surgery and the development of infectious complications. The majority of endophthalmitis cases occurred 24 months after surgery (Table 5).

None of the trabeculectomies in our study were performed in an inferior location or were associated with contact lens use.

Trabeculectomy with MMC has been associated with the development of chronic hypotony and vision loss in adults ${ }^{33}$. Hypotonic maculopathy is especially prevalent

in young adults with pronounced myopia ${ }^{33,34}$. In our series, only three eyes of a total of 114 developed overfiltration, and there was no ocular hypotony (intraocular pressure $<4 \mathrm{~mm} \mathrm{Hg}$ ) in these eyes. This low frequency was also described by other authors ${ }^{17,23,25}$, likely because children have a vigorous healing response. The downside of this vigorous healing response is the complete scarring of the filtration site. 
In conclusion, our study suffers from the limitations of a retrospective series that has no control group. However, the long-term follow-up of our patients (mean of five years in the successfully treated group) compared to other studies allows some conclusions to be drawn. Trabeculectomy with adjunctive mitomycin is an effective treatment for many pediatric glaucoma patients, including those with developmental anomalies such as AR disease. Bleb-related endophthalmitis is a serious risk related to this procedure in children, but its frequency is no higher than that seen in adults. Overfiltration and hypotonic maculopathy are complications rarely observed after trabeculectomy with adjunctive MMC treatment for primary congenital or other childhood glaucomas.

\section{REFERENCES}

1. Jaafar MS. Care of infantile glaucoma patient. Ophthalmology annual. New York: Raven Press. 1988;7:15-37.

2. Dickens CJ, Hoskins HD. Diagnosis and treatment of congenital glaucoma. In: Ritch R, Shields MB, Krupin T, eds. The Glaucomas. St. Louis: Mosby; 1989.

3. Anderson DR. Trabeculotomy compared to goniotomy for glaucoma in children. Ophthalmol. 1983;90:805-6.

4. Luntz MH, Livingston DG. Trabeculotomy ab externo and trabeculectomy in congenital and adult onset glaucoma. Am J Ophthalmol 1977; 83: 174-9.

5. Beauchamp GR, Parks MM. Filtering surgery in children: barriers to success. Ophthalmol. 1979;86:170-80.

6. Inaba Z. Long-term results of trabeculectomy in the Japanese: an analysis by life-table method. Jpn J Ophthalmol 1982;26:361-73.

7. Gressel MG, Heuer DK, Parrish II RK. Trabeculectomy in young patients. Ophthalmol. 1984;91:1242-6.

8. Debnath SC, Teichmann KD, Salamah K. Trabeculectomy versus trabeculotomy in congenital glaucoma. Br J Ophthalmol. 1989;73:60811.

9. Burke JP, Bowell R. Primary trabeculectomy in congenital glaucoma. Br J Ophthalmol. 1989;73:186-90.

10. Gressel MG, Parrish II RK, Folberg R. 5-Fluorouracil and glaucoma filtering surgery. I. An animal model. Ophthalmol. 1984;91:378-83.

11. Mallick KS, Hajek AS, Parrish II RK. Fluorouracil (5 FU) and cytarabine (Ara C) inhibition of corneal epithelial cell and conjunctival fibroblast proliferation. Arch Ophthalmol. 1985;103:1398-402.

12. Litin BS, Jones MA, Kwong EM, Herschler J. Effect of antineoplastic drugs on cell proliferation - individually and in combination. Ophthalmic Surg. 1985;16: 34-9.

13. Mc Guigan LJB, Quigley HA, Lutty G. The effects of D-penicillamine and daunorubicin in conjunctival fibroblast proliferation and collagen synthesis. Invest Ophthalmol Vis Sci. 1988;29:112-8.

14. Yamamoto T, Varani J, Soong HK, Lichter PR. Effects of 5-fluorouracil and mitomycin $\mathrm{C}$ on cultured rabbit subconjunctival fibroblasts. Ophthalmol. 1990; 97:1204-10.

15. Zalish M, Leiba H, Oliver M. Subconjunctival injections of 5-fluorouracil following trabeculectomy for congenital and infantile glaucoma. Ophthalmic Surg. 1992;23:203-5.

16. Quigley HA. Results with trabeculotomy and study of reversible cupping. Ophthalmol. 1982;89:219-26.

17. Susanna R, Oltrogge EW, Carani JCE, Nicolela MT. Mitomycin as adjunct chemotherapy in congenital and developmental glaucoma. J Glaucoma. 1995;4: 151-7.

18. McPherson SD Jr, Berry DP. Goniotomy vs. external trabeculotomy for developmental glaucoma. Am J Ophthalmol. 1983;95:427-31.
19. Katz GJ, Higginbotham EJ, Lichter PR et al. Mitomycin C versus 5 -fluorouracil in high risk glaucoma filtering surgery. Ophthalmol. 1995; 102:1263-9.

20. Kitazawa Y, Kawase K, Matsushita H, Minobe M. Trabeculectomy with mitomycin. A comparative study with Fluorouracil. Arch Ophthalmol. 1991;109: 1693-8.

21. Lamping KA, Belkin JK. 5-Fluorouracil and Mitomycin C in pseudophakic patients. Ophthalmol. 1995;102:70-5.

22. Prata JA Jr, Minckler DS, Baerveldt G. Trabeculectomy in pseudophakic patients: postoperative 5-fluorouracil versus intraoperative mitomycin C antiproliferative therapy. Ophthalmic Surg. 1995;26:73-7.

23. Beck AD, Wilson WR, Lynch MG, Lynn MJ, Noe R. Trabeculectomy with adjunctive mitomycin $\mathrm{C}$ in pediatric glaucoma. Am J Ophthalmol. 1998; 126: 648-57.

24. Sidoti PA, Belmonte SJ, Liebmann JM, Ritch R. Trabeculectomy with Mitomycin-C in The Treatment of Pediatric Glaucomas. Ophthalmol. 2000;107:422-9.

25. Mandal AK, Walton DS, John T, Jayagandan A. Mitomycin C-augmented trabeculectomy in refractory congenital glaucoma. Ophthalmol. 1997; 104:996-1001.

26. Miller MH, Rice NS. Trabeculectomy combined with $\beta$-irradiation for congenital glaucoma. Br J Ophthalmol. 1991;75:584-90.

27. Wahee US, Ritterband DC, Greenfield DS, Liebmamm JM, Sidoti AO, Ritch R. Bleb-related ocular infection in children after trabeculectomy with mitomycin C. Ophthalmol. 1997;104:2117-20.

28. Wallace DK, Plager DA, Synder SK, Raiesdana A, Helveston EM, Ellis FD. Surgical results of secondary glaucomas in childhood. Ophthalmol. 1998;105:101-111.

29. Wells AP, Cordeiro MF, Bunce C, Khan PT. Cystic bleb formation and related complications in limbus- versus fornix-based conjunctival flaps in pediatric and young adult trabeculectomy with mitomycin. Ophthalmol. 2003;110:2192-7.

30. Wolner B, Liebmann JM, Sassani JW, Ritch R, Speaker M, Marmor M. Late bleb-related endophthalmitis after trabeculectomy with adjunctive 5-fluorouracil. Ophthalmol. 1991;98:1053-60.

31. Higginbotham EJ, Stevens RK, Musch DC. Bleb-related endophthalmitis after trabeculectomy with mitomycin C. Ophthalmol. 1996;103:6506.

32. Greenfield DS, Suver IJ, Miller MP, Kangas TA, Palmberg PF, Flynn HW. Endophthalmitis after filtering surgery with mitomycin. Arch Ophthalmol. 1996; 114:943-9.

33. Jampel HD, Pasquale RL, Dibernardo C. Hypotony maculopathy following trabeculectomy with mitomycin C [letter]. Arch Ophthalmol. 1992;110:1049-50.

34. Stamper RL, McMenemy MG, Lieberman MF. Hypotonous maculopathy after trabeculectomy with subconjunctival 5-fluorouracil. Am J Ophthalmol. 1992; 114:544-53. 